\title{
INVESTIGATION OF SORPTION OF CHROMATE ION ON A SYNTHETIC HEMATITE
}

\author{
V. T. BODUNDE ${ }^{1 *}$, F. A. ADEKOLA ${ }^{2}$, and N. ABDUS-SALAM ${ }^{2}$ \\ ${ }^{1}$ Department of Chemistry, Kwara State University, Malete, Nigeria \\ Email: tovex2001@yahoo.com \\ ${ }^{2}$ Department of Chemistry, University of Ilorin, PMB 1515, Ilorin, Nigeria
}

\begin{abstract}
A Hematite sample was synthesized using precipitation method and it was characterized using a combination of analytical techniques such as infrared spectroscopy, X-ray diffractometry and atomic absorption spectrometry. The hematite was then studied for its potential to remove chromate ion from aqueous solution. The maximum adsorption capacity was found to be $1.91 \mathrm{mg} / \mathrm{g}$. The influence of contact time, ionic strength and $\mathrm{pH}$ on the sorption capacity was also investigated. Maximum adsorption was observed in the range $\mathrm{pH} 4.0$ and $\mathrm{pH} 6.0$ at an optimum time of 3 hours 20 mins. The experimental results were finally analyzed using Langmuir, Freundlich and Temkin isotherms. The Temkin isotherm was found to have the most satisfactory fitting for the sorption data. The sorption kinetics was studied for the pseudo-first order and pseudo-second order models.
\end{abstract}

Key Words: Heavy metals; Adsorption; point of zero charge; Freundlich; Langmuir and Temkin Isotherms.

\section{INTRODUCTION}

Chromium is one of the most widely distributed heavy metals in the earth's crust. It is usually found in two oxidation states i.e., $\mathrm{Cr}(\mathrm{III})$ and $\mathrm{Cr}(\mathrm{VI})$. Chromium is required in small quantities as an essential trace metal nutrient and its deficiency may result in several physiological disorders. Most of the biological tissues contain Cr(III) which is usually considered to be nontoxic, whereas $\mathrm{Cr}(\mathrm{VI})$ is a highly toxic form of the metal to organisms.

Chromium (Cr) pollution is widely of concern throughout the world because of its large magnitude and known adverse health effects (Deng et al. 1995). Dregs of chromium are produced during manufacturing of Cr-containing alloys and salts. These waste materials usually contain a significant amount of chromium (James 1996), which could be leached because of water filtration and/or ground water fluctuation. Chromium contamination of soils and water is also caused by improper disposal of $\mathrm{Cr}$-containing waste-water and sludge produced from corrosion inhibition and electroplating processes.

Chromium exists mainly as hexavalent chromate $(\mathrm{Cr}(\mathrm{VI}))$ When released into the environment and trivalent forms $(\mathrm{Cr}(\mathrm{III}))$. Chromium species at different oxidation states show substantially different physical and chemical properties. $\mathrm{Cr}(\mathrm{VI})$ is an oxidant with high solubility and mobility in soils and aquifers, as well as high toxicity to human and ecosystems; whereas $\mathrm{Cr}$ (III) has lower mobility, mostly precipitated as hydroxides or adsorbed onto mineral surfaces. As a result, contamination of $\mathrm{Cr}(\mathrm{VI})$ is often controlled by $\mathrm{Cr}(\mathrm{VI})$ reduction into $\mathrm{Cr}$ (III) using various reducing agents, such as zero-valent iron (Blowes et al. 1997), iron(II) (Eary et al. 1988a) and organic compounds, (Bartlett et al. 1983).

Reduction of $\mathrm{Cr}(\mathrm{VI})$ to $\mathrm{Cr}(\mathrm{III})$ is a viable option to remediate sites contaminated with $\mathrm{Cr}(\mathrm{VI})$. $\mathrm{Fe}(\mathrm{II})$ is a commonly used reductant for $\mathrm{Cr}(\mathrm{VI})$ in wastewater treatment. $\mathrm{Cr}(\mathrm{VI})$ reduction by $\mathrm{Fe}(\mathrm{II})$ is of interest because $\mathrm{Fe}(\mathrm{II})$ is found in various types of soil (such as in hematite) and is a primary electron donor in subsurface environments. Fe(II) can be released from primary silicates and oxides such as muscovite and biotite, and secondary layer silicates such as vermiculite, smectites, dilorites (Eary et al. 1988b) and oxides such as hematite, magnetite and goethite. $\mathrm{Cr}(\mathrm{VI})$ reduction by $\mathrm{Fe}(\mathrm{II})$ near neutral $\mathrm{pH}$ to produce their separate hydroxide solids can be described by the following stoichiometric reaction:

$$
4 \mathrm{H}_{2} \mathrm{O}+\mathrm{CrO}_{4}^{2-}+3 \mathrm{Fe}^{2+}+4 \mathrm{OH}^{-} \rightarrow 3 \mathrm{Fe}(\mathrm{OH})_{3}
$$

$\mathrm{Cr}(\mathrm{VI})$ reduction by $\mathrm{Fe}(\mathrm{II})$ has been reported to be very rapid and stoichiometric in solution, (Eary et al. 1988a), (Fendorf et al. 1996). It has also been reported to lead to the formation of mixed iron/chromium solid solution of the form $\mathrm{Fe}_{\mathrm{x}} \mathrm{Cr}_{1-\mathrm{x}}(\mathrm{OH})_{3}$, (Rai et al. 1987).

\section{HEMATITE}

Hematite is the mineral form of iron (III) oxides $\left(\mathrm{Fe}_{2} \mathrm{O}_{3}\right)$. It is one of several iron oxides. Hematite is a very common mineral, coloured black to steel or silvergrey, brown to reddish brown or red. It is mined as the main ore of iron. Varieties include kidney ore, martite (Pseudomorphs), iron rose and specularite. While the forms of hematite vary, they all have a rust-red streak. 
Hematite is harder than pure iron, but much more brittle. Hematite is a part of a complex solid solution oxyhyroxide system having various degrees of water, hydroxyl group, and vacancy substitution that affect the mineral's magnetic and crystal chemical properties (http://www.mindat.org/min-1856 html).

\section{SOURCES OF HEMATITE}

Huge deposits of hematites are found in banded iron formations. Grey hematite is typically found in places where there has been standing water or mineral hot springs, such as those in Yellowstone. The mineral can precipitate out of water and collect in layers at the bottom of a lake, spring or other standing water. Hematite can also occur without water, however, usually as the result of volcanic activity. Clay-sized hematite crystals can also occur as a secondary mineral formed by weathering processes in soil along with other iron oxides or oxyhydroxides such as goethite (http:// www.mindat.org/min-1856 html).

\section{SYNTHESIS OF HEMATITE}

Hematite can be prepared by a variety of routes. The most recent ones are: solvothermal synthesis, forced hydrolysis, transformation of ferrihydrite in aqueous solution, hydrothermal synthesis and precipitation.

\section{PREPARATION BY FORCED HYDROLYSIS}

Forced hydrolysis of acid $\mathrm{Fe}^{3+}$ solutions involves hydrolyzing $\mathrm{Fe}\left(\mathrm{NO}_{3}\right)_{3}, \mathrm{Fe}\left(\mathrm{ClO}_{4}\right)_{3}$ or $\mathrm{FeCl}_{3}$ solutions at a temperature close to $100^{\circ} \mathrm{C}$ under strongly acidic conditions ( $\mathrm{pH} \mathrm{1-2).} \mathrm{It} \mathrm{is} \mathrm{believed} \mathrm{that} \mathrm{hematite} \mathrm{forms}$ under these condition via Fe(III) hydroxyl polymers which transform through internal rearrangement and dehydration to hematite (Schwertmann et al. 2007).

\section{PREPARATION BY TRANSFORMATION OF FERRIHYDRITE}

Hematite production by transformation of ferrihydrite starts with precipitation of ferrihydrite which is then converted to hematite in aqueous suspension by rearrangement and dehydration within ferrihydrite aggregates. This transformation takes place under weakly acid to weakly alkaline conditions. Although ferrihydrite has a low solubility in this $\mathrm{pH}$ range, some dissolution may occur leading to goethite precipitation in solution. Such precipitations, therefore, often contain some goethite mixed with the hematite particularly if the $\mathrm{pH}$ deviates substantially from neutrality. To avoid goethite, it is essential to conduct all operations at the transformation temperatures $\left(>70^{\circ} \mathrm{C}\right)$ or to raise the temperature to above $100^{\circ} \mathrm{C}$ in a pressure vessel (Schwertmann et al. 2007).

\section{PREPARATION BY SOLVOTHERMAL PROCESS}

$\mathrm{Lu}$ et al. (2006) studied the synthesis of hematite by a solvothermal process. $100 \mathrm{ml} 1.2 \mathrm{M} \mathrm{NaOH}$ solution was dropped into $100 \mathrm{ml} 0.6 \mathrm{M} \mathrm{FeCl}_{3} \cdot 6 \mathrm{H}_{2} \mathrm{O}$ solution under magnetic stirring at $60^{\circ} \mathrm{C}$ to form a dark-red transparent $\mathrm{Fe}(\mathrm{OH})_{3}$ solution. The solution was diluted with water to $250 \mathrm{ml}$, into which $6.3 \mathrm{~g}$ of sodium dodecyl benzene sulfonate was added to produce a yellow precipitate. The precipitate was collected by filtration and dried at $60^{\circ} \mathrm{C}$ for $24 \mathrm{hr}$. The dried complex was dissolved into $72 \mathrm{ml}$ dimethyl benzene to form an organic solution and the solution was poured into Teflon-lined autoclaves and heated at $200^{\circ} \mathrm{C}$ for $6 \mathrm{hr}$. The product was collected by centrifugation, washed with ethanol and deionized water and dried at ambient temperature.

\section{HYDROTHERMAL SYNTHESIS OF HEMATITE}

Wang et al. (2003) prepared well-dispersed $\alpha-\mathrm{Fe}_{2} \mathrm{O}_{3}$ nanoparticles by a low-temperature hydrothermal method. Analytical grade iron chloride $\left(\mathrm{FeCl}_{3} \cdot 6 \mathrm{H}_{2} \mathrm{O}\right)$ and cetyltrimethyl ammonium bromide (CTAB, $0.6 \mathrm{~g}$ ) were dissolved in $40 \mathrm{ml}$ of distilled water. The whole mixture was stirred for $30 \mathrm{~min}$ to form a homogeneous solution before it was transferred into a Teflon-lined stainless steel autoclave, sealed and maintained at $80^{\circ} \mathrm{C}$ of $10 \mathrm{hrs}$. Finally, it was heated to $150-180^{\circ} \mathrm{C}$ for 12 hours with a heating ramping of $1{ }^{\circ} \mathrm{C} / \mathrm{min}$. after the reaction was completed; the resulting red brown solid product was centrifuged, rinsed with distilled water repeatedly in order to purify the product and finally dried at $100^{\circ} \mathrm{C}$ under vacuum. The crystalline phase was identified by x-ray diffraction (XRD) and the morphology of the sample was examined by transmission electron microscopy (TEM).

\section{LITERATURE ON SORPTION OF CHROMATE IONS ON HEMATITE THE USE OF HEMATITE FOR CHROMIUM (VI) REMOVAL}

The ability of hematite to remove $\mathrm{Cr}(\mathrm{VI})$ from aqueous solutions has been studied at different concentrations, temperatures and $\mathrm{pH}$. The maximum removal (97\%) was observed at $40^{\circ} \mathrm{C}$ and $\mathrm{pH} 2.7$ with initial concentrations of $19.23 \mu \mathrm{mol} / \mathrm{L} \mathrm{Cr}(\mathrm{VI})$ and $40 \mathrm{~g} / \mathrm{L}$ hematite. The equilibrium data obey the Langmuir isotherm for the present system. The reaction dynamics have been studied and the process involves both film and pore diffusion to different extents. Mass transfer and diffusion coefficients have been determined. Thermodynamic parameters indicate the spontaneous and 
endothermic nature of the process. The uptake of $\mathrm{Cr}(\mathrm{VI})$ increases as $\mathrm{pH}$ decreases and the maximum removal has been attributed to the formation of positively charged aquacomplexes of iron at the surface and a subsequent interaction with the dominant $\mathrm{HCrO}_{4}{ }^{-}$ species. An empirical equation has been developed to predict equilibrium adsorption capacity from knowledge of equilibrium adsorbate concentration (Singh et al. 1993).

Sorption of $\mathrm{Cr}(\mathrm{VI})$ onto natural iron and aluminum(oxy)hydroxides: Effects of $\mathrm{pH}$, ionic strength and initial concentration

The performances of removal of hexavalent chromium from aqueous solution were studied using three different oxy-hydroxides: hematite, goethite and $\alpha$ alumina. Batch experiments were conducted to measure the effects on adsorption of $\mathrm{Cr}(\mathrm{VI})$ of different parameters such as $\mathrm{pH}$ of the medium, ionic strength, and initial concentration. Results showed that the adsorption of $\mathrm{Cr}(\mathrm{VI})$ depends strongly on the $\mathrm{pH}$, but was independent of ionic strength for hematite and goethite. For $\alpha$-alumina, adsorption is strongly dependent on $\mathrm{pH}$ values and ionic strength. Equilibrium studies showed that $\mathrm{Cr}(\mathrm{VI})$ had a high affinity in an acidic medium, but decreased as solution $\mathrm{pH}$ increased. Equilibrium isotherms were measured experimentally. Results were analyzed by the Langmuir and Freundlich equations using linearized correlation coefficient at room temperature. The characteristic parameters for each isotherm have been determined. The Langmuir equation was found to fit the equilibrium data for $\mathrm{Cr}(\mathrm{VI})$ adsorption (Ajouyed et al. 2010).

\section{DFT studies of $\mathrm{Cr}(\mathrm{VI})$ complex adsorption on hydroxylated hematite surfaces}

The adsorption structures of $\mathrm{Cr}(\mathrm{VI})$ species on hydroxylated $\alpha-\mathrm{Fe}_{2} \mathrm{O}_{3}$ were investigated using density functional theory within a periodic slab model. A broad structural survey of $\mathrm{H}_{2} \mathrm{CrO}_{4}, \mathrm{HCrO}_{4}{ }^{-}$and $\mathrm{CrO}_{4}{ }^{2-}$ adsorbed on different surface sites was carried out. Chromate species adsorb on the hydroxylated surface via an outer-sphere mechanism through $\mathrm{H}$-bonding and ion-dipole attraction. The most stable structure for $\mathrm{H}_{2} \mathrm{CrO}_{4}$ reveals strong $\mathrm{H}$-bonding to surface and between adsorbates. For $\mathrm{HCrO}_{4}{ }^{-}$, a configuration that shows both $\mathrm{H}$-bonding and $\mathrm{Cr}-\mathrm{O} \cdots \mathrm{H}-\mathrm{O}-\mathrm{Fe}$ ion-dipole interaction is the most favored. In the case of $\mathrm{CrO}_{4}{ }^{2-}$, the most favored adsorption configuration shows the complex standing on the surface with a $\mathrm{Cr}-\mathrm{O}$ bond aligned on $\mathrm{OH}$, presenting the strongest $\mathrm{Cr}-\mathrm{O} \cdots \mathrm{H}-\mathrm{O}$ $\mathrm{Fe}$ interaction. In these three species, $\mathrm{CrO}_{4}{ }^{2-}$ displays the strongest interaction with the hydroxylated surface with no tendency toward reduction observed, in accordance with experiment (Yin et al. 2009).

\section{MATERIALS AND METHOD}

All chemicals and reagents used were analytical grade and were used without further purification.

\section{SYNTHESIS OF HEMATITE}

Fourty grams of $\mathrm{Fe}\left(\mathrm{NO}_{3}\right)_{3} \cdot 9 \mathrm{H}_{2} \mathrm{O}$ was dissolved in $500 \mathrm{ml}$ of doubly distilled water preheated to $90^{\circ} \mathrm{C}$ and it was precipitated with $300 \mathrm{ml} 1 \mathrm{M} \mathrm{KOH}$ preheated to $90^{\circ} \mathrm{C}$ and $50 \mathrm{ml} 1 \mathrm{M} \mathrm{NaHCO}_{3}$ preheated to $90^{\circ} \mathrm{C}$ was added. The suspension formed was held in a closed polythene flask at $90^{\circ} \mathrm{C}$ for $48 \mathrm{hrs}$ in an oven (Schwertmann et al. 2007).

\section{CHARACTERIZATION OF HEMATITE SPECIFIC GRAVITY}

An empty specific gravity bottle was weighed (W1) and the weighed bottle was filled with water to determine the volume. The bottle was emptied, dried and then filled with hematite sample and reweighed (W2). Specific gravity is given by ratio of difference in masses to the volume of the bottle (http://www.eformulae.com/chemistry/specific.php).

$$
\text { Specific Gravity }=\frac{\mathrm{W} 2-\mathrm{W} 1}{\mathrm{~V}}
$$

\section{SPECTROSCOPIC AND CRYSTALLOGRAPHIC INFORMATION}

Both the pre-sorbed and after-sorbed hematites were subjected to infrared spectroscopic measurement. While, $\mathrm{X}$-ray diffractometry (XRD) was also used to obtain crystallographic information on the hematite sample.

\section{SURFACE-CHEMICAL PROPERTIES DETERMINATION OF POINT OF ZERO CHARGE MASS TITRATION}

Various masses of the hematite sample i.e., 0.1, 0.5, $1.0,1.5$ and $2.0 \mathrm{~g}$ were suspended in $\mathrm{KNO}_{3}$ solution of different concentrations $(0.1,0.01,0.001 \mathrm{M})$. The initial $\mathrm{pH}$ of each sample solution was taken and the solution was allowed to equilibrate for $24 \mathrm{hr}$ and $\mathrm{pH}$ was measured. A few drops of $0.01 \mathrm{M} \mathrm{HNO}_{3}$ solution were added to each solution with the aid of a micropipette to adjust the $\mathrm{pH}$ to 7 . The sample solution was agitated again with a mechanical shaker for $24 \mathrm{hrs}$ after which the $\mathrm{pH}$ was taken and few drops of $0.01 \mathrm{M} \mathrm{KOH}$ were added to adjust the $\mathrm{pH}$ of the solution to 10 . The 
Bodunde et al.: Sorption of Hematite

Table 1. Physico-chemical properties of synthesized hematite.

\begin{tabular}{lc}
\hline \multicolumn{1}{c}{ Parameters } & Results \\
\hline Colour & Reddish brown \\
Texture & Fine \\
Density $\left(\mathrm{g} / \mathrm{cm}^{3}\right)$ & 3.027 \\
$\%$ by weight of $\mathrm{Fe}$ & $63.7 \%$ \\
$\%$ by weight of $\mathrm{Mn}$ & $2.0 \%$ \\
$\%$ by weight of $\mathrm{Cu}$ & $1.5 \%$ \\
$\%$ by weight of $\mathrm{Zn}$ & $1.2 \%$ \\
$\%$ by weight of $\mathrm{Mg}$ & $0.3 \%$ \\
$\mathrm{PZC}$ & $7.2-10.4$ \\
pH & 6.26 \\
$\%$ yield & 91.8 \\
\hline
\end{tabular}

solution was agitated for $24 \mathrm{hrs}$ and $\mathrm{pH}$ was re-taken. The values of the different masses of the hematite sample were plotted against $\mathrm{pH}$ obtained at different concentrations of $\mathrm{KNO}_{3}$ solution for each of the stages (i.e., neutral, acidic and alkaline) separately and the point at which the $\mathrm{pH}$ became constant with increasing mass gave the point of zero charge (Noh et al. 1989).

\section{ANALYSIS OF CHROMIUM IN AQUEOUS SOLUTION}

Chromium was analysed in aqueous solution spectrophotometrically. It involved the determination of the maximum absorption spectrum and standard calibration graph for subsequent measurements.

\section{DETERMINATION OF MAXIMUM WAVELENGTH}

The absorption spectrum of chromate solution was determined to select the wavelength of maximum absorbance. The absorbance of the stock solution, i.e., $1,000 \mathrm{mg} / \mathrm{l}$ of chromate solution, was taken on a Campec M106 UV-Spectrophotometer at different wavelengths (419-459.5 nm). The absorbances obtained were plotted against the corresponding wavelength. The wavelength $(\lambda \max )$ corresponding to the maximum absorbance was then selected for maximum absorbance measurements. The graph of absorbance versus the wavelength is presented in Fig. 14.

Table 2. Selected Infrared data for synthesized hematite, (Schwertmann et al. 1985).

\begin{tabular}{ll}
\hline Peaks & \multicolumn{1}{c}{ Functional Groups } \\
\hline 2,854 & O-H Stretch. \\
$722-973$ & Characteristic band of hematite \\
& and O-H deformation. \\
\hline
\end{tabular}

Table. 3 Infrared data for hematite sample after sorption, (Schwertmann et al. 1985).

\begin{tabular}{lc}
\hline Peaks & Functional Groups \\
\hline $2,853-2,923$ & $\begin{array}{c}\text { Indicating the presence of } \\
\text { hydroxyl stretch } \\
\text { Characteristics band of } \\
\text { hematite and O-H deformation }\end{array}$ \\
\hline
\end{tabular}

\section{CALIBRATION GRAPH OF CHROMATE SOLUTION}

The data of absorbance against concentration of the standard solution of chromium was taken. The best straight line is fitted for the data using regression analysis. The graph is illustrated in Fig. 15 with correlation coefficient $\left(\mathrm{R}^{2}=0.9966\right)$.

\section{SORPTION EXPERIMENT}

The adsorption experiments were categorized into two types namely:

1. Adsorption Capacity

2. Adsorption Kinetics

\section{DETERMINATION OF ADSORPTION CAPACITY OF HEMATITE FOR CHROMATE SOLUTION}

The sorption capacity was determined using varied initial concentration of chromate solution (30-70 ppm) while maintaining the adsorbent (hematite) dosage at $0.5 \mathrm{~g}$ per $20 \mathrm{ml}$ of solution. Maximum time of agitation of $24 \mathrm{hrs}$ was used. The mixture of each flask was filtered and the absorbance of the filtrate from each flask was taken. The residual concentration of the filtrate was determined from the calibration curve. The amount sorbed was calculated from the equation (Megat et al. 2007; Horsfall et al. 2005)

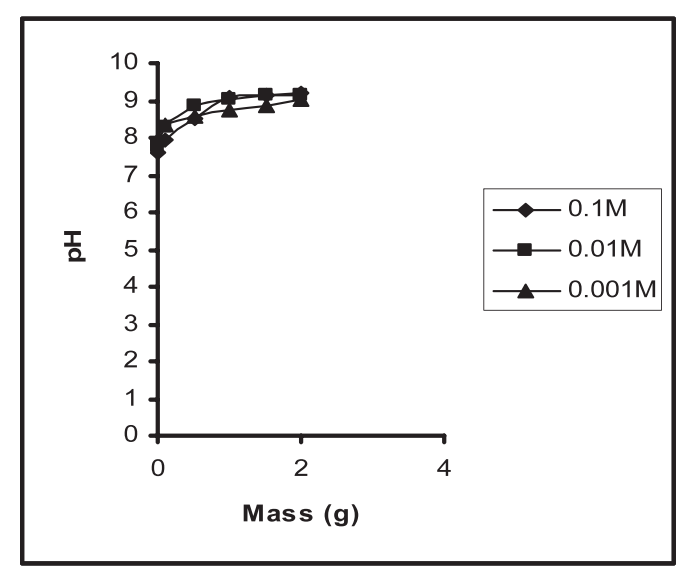

FIG. 1. Graph of $\mathrm{pH}$ versus mass of sample immediately after equilibration. 


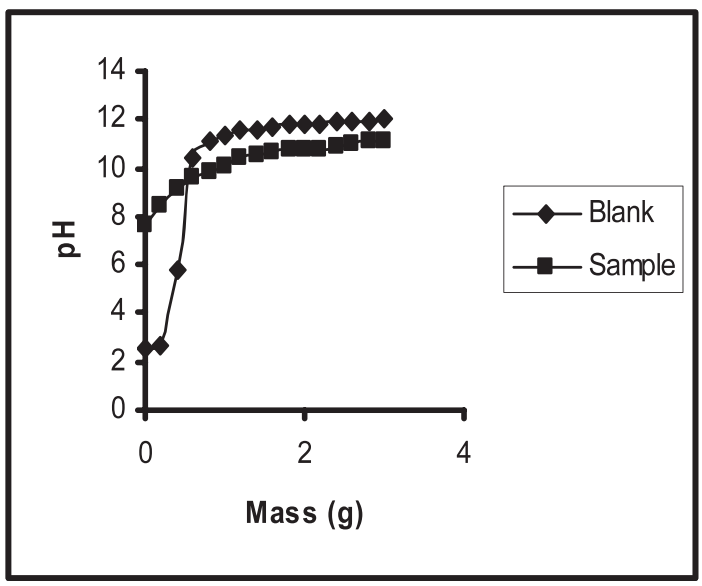

FIG. 2. Graph of $\mathrm{pH}$ versus volume with $0.1 \mathrm{M} \mathrm{KNO}_{3}$.

$$
\mathrm{q}_{\mathrm{e}}=\frac{(\mathrm{Ci}-\mathrm{Cf})(\mathrm{mg} / \mathrm{l}) \times \mathrm{V}(\mathrm{l})}{\mathrm{M}(\mathrm{g})}
$$

where

$\mathrm{q}_{\mathrm{e}}=$ Amount sorbed at equilibrium (mg/g)

$\mathrm{C}_{\mathrm{i}}=$ Initial Concentration of chromate solution $(\mathrm{mg} / \mathrm{l})$

$\mathrm{C}_{\mathrm{f}}=$ Final Concentration after equilibrium (mg/l)

$\mathrm{V}=$ Volume of chromate solution used (1)

$\mathrm{M}=$ Mass of hematite used (g)

The equilibrium amount sorbed was plotted against initial concentration of solutions to find the equilibrium point where an increase in concentration does not have an effect on the quantity sorbed. The equilibrium concentration was used constantly for sorption kinetics.

\section{DETERMINATION OF ADSORPTION KINETICS}

The effects of $\mathrm{pH}$, reaction time and ionic strength were investigated on the sorption capacities of hematite using the following procedures:

Effect of contact time.-The effect of reaction time on sorption capacity was studied by agitating the solution

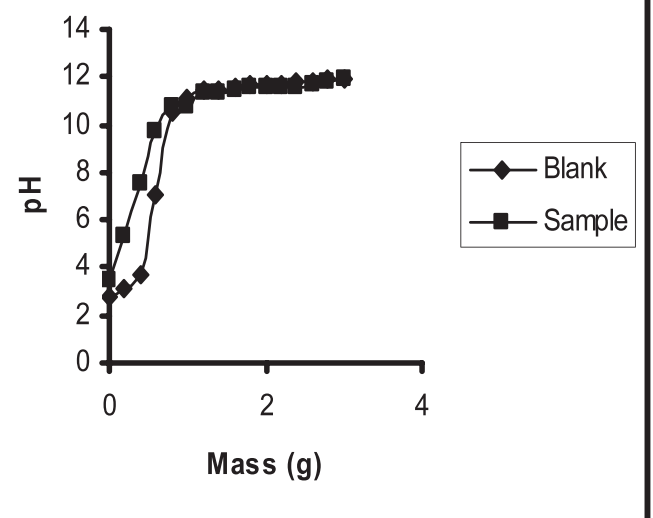

FIG. 3. Graph of $\mathrm{pH}$ versus volume with $0.01 \mathrm{M} \mathrm{KNO}_{3}$.

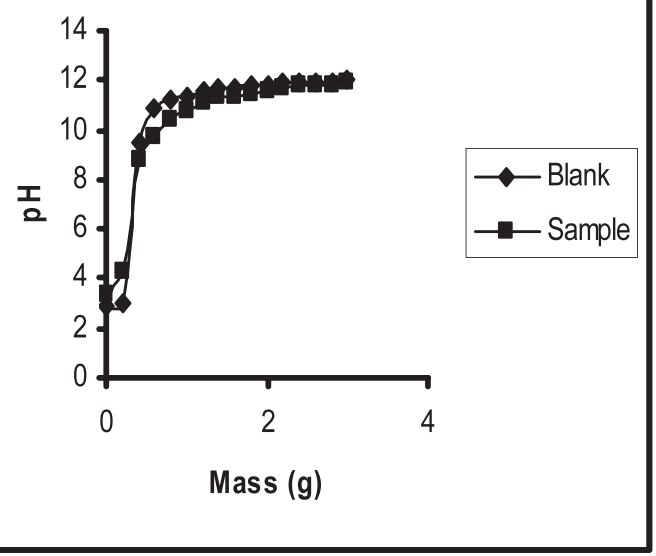

Fig. 4. Graph of $\mathrm{pH}$ versus volume with $0.001 \mathrm{M} \mathrm{KNO}_{3}$.

at different time intervals i.e., $40 \mathrm{~min}, 80 \mathrm{~min}, 120 \mathrm{~min}$, $160 \mathrm{~min}, 200 \mathrm{~min}$ and $240 \mathrm{~min}$. The concentration and adsorbent dosage were kept constant i.e., equilibrium concentration as obtained above. Absorbance values were measured and the final concentrations were obtained from the calibration curve. The quantity fixed was then calculated. A graph of quantity fixed was plotted against time.

Effect of ionic strength.-The effect of ionic strength was studied by varying the concentration of $\mathrm{KNO}_{3}$ (0.001 M, 0.005 M, 0.01 M, 0.05 M and 0.1 M). The concentration, contact time and adsorbent dosage were kept constant, i.e., equilibrium concentration as obtained above. Absorbance values were measured and the final concentrations were obtained from the calibration curve. The quantity fixed was then calculated. A graph of quantity fixed was plotted against ionic strength.

Effect of $p H$.- The sorption capacity was studied over a $\mathrm{pH}$ range of 4 to 9 and the $\mathrm{pH}$ was adjusted by addition of $0.01 \mathrm{M} \mathrm{HNO}_{3}$ or $0.01 \mathrm{M} \mathrm{KOH}$. The concentration, contact time, ionic strength and adsor-

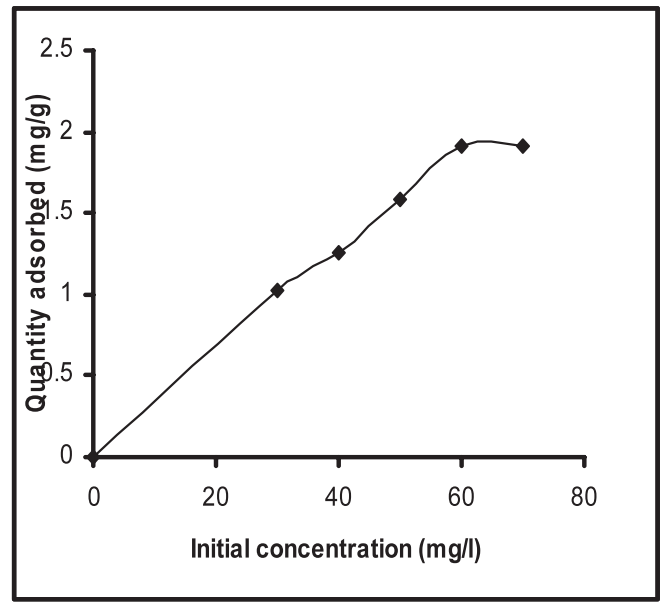

FIG. 5. Graph of Quantity sorbed versus initial concentration. 


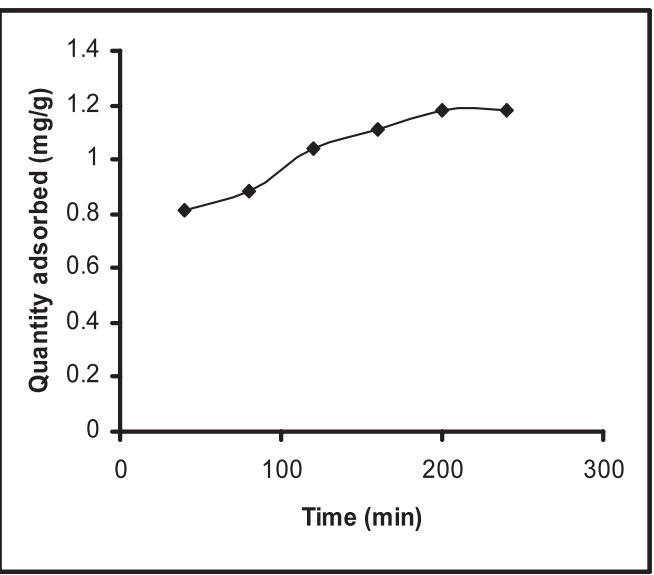

FIG. 6. Graph of quantity adsorbed against time.

bent dosage were kept constant i.e., equilibrium concentration as obtained above. Absorbance values were measured and the final concentrations were obtained from the calibration curve. The quantity fixed was then calculated. A graph of quantity fixed was plotted against $\mathrm{pH}$.

\section{RESULTS AND DISCUSSION PHYSICAL PROPERTIES OF HEMATITE}

Low percentages of $\mathrm{Mn}, \mathrm{Cu}, \mathrm{Zn}$ and $\mathrm{Mg}$ recorded can be accounted for by the presence of these ions as impurities in the reagents used (Table 1)

\section{PERCENTAGE YIELD OF HEMATITE}

The percentage yield of the synthesized hematite was calculated to be $91.8 \%$ and this is similar to the result earlier obtained by P. Sergey Gubin (2009), using the same precipitation method.

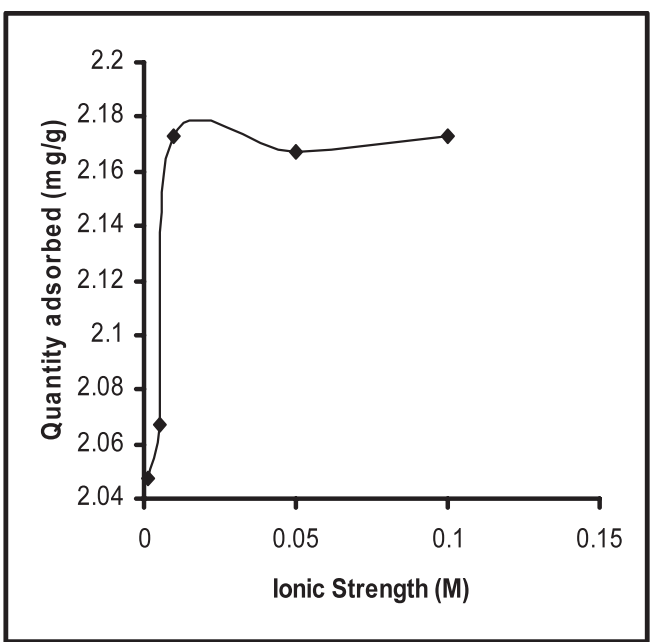

FIG. 7. Graph of quantity adsorbed against ionic strength.

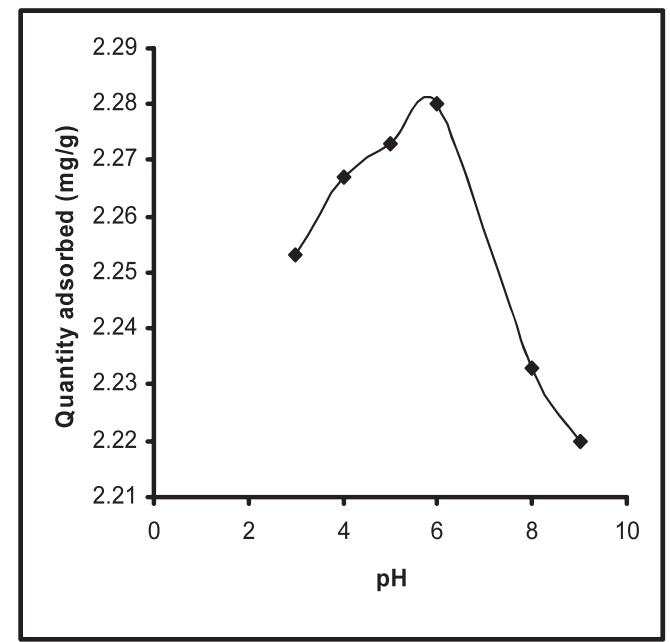

FIG. 8. Graph of quantity adsorbed against $\mathrm{pH}$.

\section{SPECTROSCOPIC STUDIES}

Infrared spectra of the hematite sample, which indicates the presence of a characteristic peak of hematite at $722-973 \mathrm{~cm}^{-1}$ (Tables 2 and 3)

The XRD result shows the presence of hematite with rhombohedra shape. In the infrared spectra, peak absorption between 2,853-2,923 indicates the presence of hydroxyl stretch and peak absorption at 722-973 shows the characteristic band of the hematite and $\mathrm{O}-\mathrm{H}$ deformation. It was observed from these results that a well formed hematite was synthesized.

\section{DETERMINATION OF POINT OF ZERO CHARGE USING MASS TITRATION METHOD}

After equilibration, the point of zero charge was observed to range from 8.5-9.0 for different ionic strengths but after acidic adjustment the point of zero charge dropped to the range 8.03-8.31. However, after

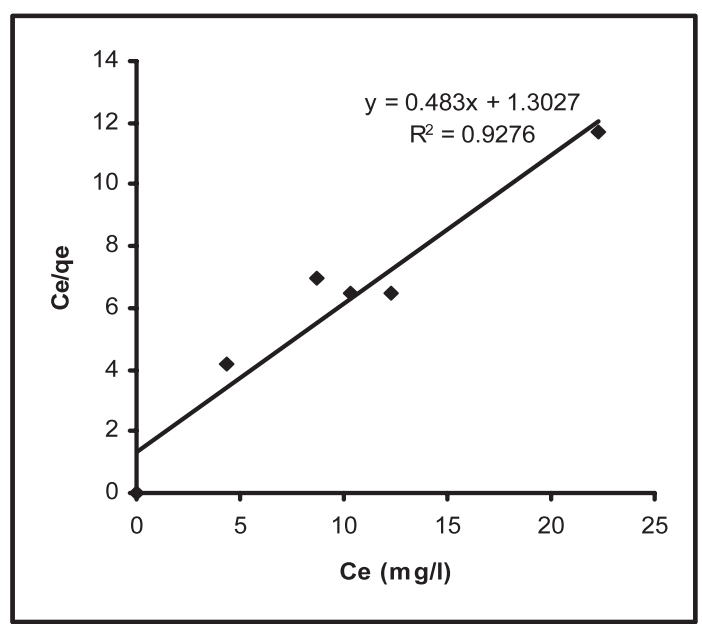

FIG. 9. Langmuir adsorption isotherm plot. 


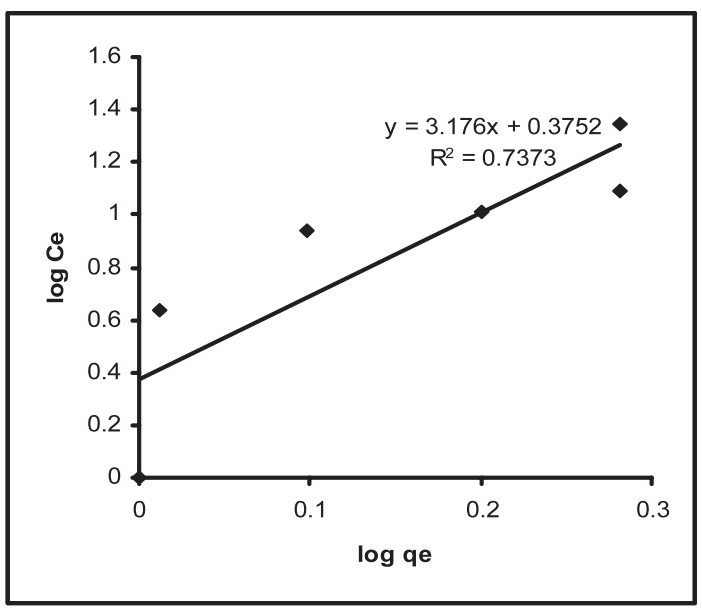

FIG. 10. Freundlich adsorption isotherm plot.

alkaline adjustment the point of zero charge increased to the range 8.86-9.03 for different ionic strengths. The values obtained for point of zero charge are in the same range as the one reported by Kosmulski (2004) (Fig. 1).

After titration, the point of zero charge was observed in the range 7.2-10.4 for different ionic strengths (Figs. 2, 3 and 4).

The effects of $\mathrm{pH}$ on chromate removal are generally related to the point of zero charge of the adsorbent. Above the point of zero charge value the adsorbent is in a monomeric anionic form and consequently have no affinity for Cr-oxyanions, (Guy et al. 2007), therefore, sorption is expected to be favourable at $\mathrm{pH}$ lower than the point of zero charge (i.e., $\mathrm{pH}<7.2$ ).

\section{ADSORPTION CAPACITY OF HEMATITE FOR CHROMATE SOLUTION}

The amount of hematite and the volume of chromate solution used were the same for all the samples i.e., $0.5 \mathrm{~g}$ and $20 \mathrm{ml}$ respectively. The initial concentration was varied between 0 and $70 \mathrm{mg} / \mathrm{l}$. It was observed that as the initial concentration is increased, the concentration increases thereby resulting in an increase in quantity adsorbed after which quantity adsorbed remains constant with increasing initial concentration (Fig. 5).The maximum adsorption capacity has been found to be $1.908 \mathrm{mg} / \mathrm{g}$.

\section{EFFECT OF CONTACT TIME}

It is clear that the metal sorption capacity increased with an increase in contact time before attaining equilibrium at $200 \mathrm{~min}$ (Fig. 6). The contact time of $200 \mathrm{~min}$ was then used for further studies.

\section{INFLUENCE OF IONIC STRENGTH}

A steady increase in the amount adsorbed was observed as the ionic strength increases until it gets to

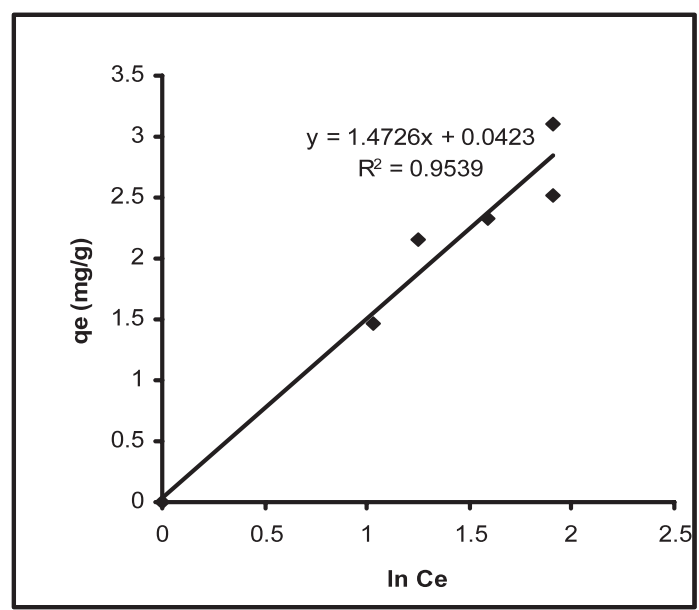

FIG. 11. Temkin adsorption isotherm plot.

a point where further increase in ionic strength has no effect on the adsorption of chromium (ionic strength $>0.01 \mathrm{M}$ ) (Fig. 7). The ionic strength of $0.01 \mathrm{M}$ was therefore retained for subsequent experiment.

\section{INFLUENCE OF PH}

An adsorption experiment was carried out at $\mathrm{pH}$ ranging from 3-9 and a steady increase in quantity adsorbed was observed as $\mathrm{pH}$ increases but quantity adsorbed reduces after $\mathrm{pH}$ of 6 indicating that chromium adsorption is favorable at a $\mathrm{pH}$ value of 6 . At this optimum $\mathrm{pH}$, the maximum chromium removal by hematite was found to be $95 \%$ and this $\mathrm{pH}$ value agreed with the work of El-Chaghaby et al. (2008). At this $\mathrm{pH}$ (below PZC), hematite is in cationic form and it has maximum affinity for chromate ions. All subsequent experiments were carried out at $\mathrm{pH}$ of 6 (Fig. 8).

\section{LANGMUIR ADSORPTION ISOTHERM}

The sorption data were fitted with the Langmuir Adsorption isotherm (Fig. 9). The Langmuir adsorption constants obtained are $\mathrm{q}_{\mathrm{m}}=2.07$ and $\mathrm{b}=0.371$ and the correlation coefficient, $\mathrm{R}^{2}=0.927$.

From the observed adsorption efficiency $\left(\mathrm{q}_{\mathrm{m}}\right)$ value, it can be concluded that the maximum adsorption corresponds to a saturated monolayer of adsorbate on adsorbent in the plane of the adsorbent surface with no transmission of adsorbate in the plane of the adsorbent surface (Krishna et al. 2002; Arivoli et al. 2006). The theoretical value of $\mathrm{q}_{\mathrm{m}}$ is in the same range as the experimental value. The observed $b$ (adsorption energy) value shows that the adsorbent prefers to bind acidic ions and that speciation predominates on sorbent characteristics when ion exchange is the predominant mechanism that takes place in the adsorption of chromium ion (Arivoli et al. 2007a). To confirm the 
Table 4. Isothermal constants and correlation coefficient.

\begin{tabular}{lccccccc}
\hline \multicolumn{1}{c}{$\mathrm{b}$} & $\mathrm{q}_{\mathrm{m}}$ & $\mathrm{K}_{\mathrm{f}}$ & $\mathrm{n}$ & $\mathrm{K}_{\mathrm{t}}$ & $\mathrm{b}_{\mathrm{T}}$ & $\mathrm{R}^{2}$ & \\
\hline Langmuir & 0.371 & 2.07 & - & - & - & - & 0.9276 \\
Freundlich & - & - & 0.8935 & 0.2321 & - & - & 0.7373 \\
Temkin & - & - & - & - & 1.029 & 1.682 & 0.9539 \\
\hline
\end{tabular}

favourability of the adsorption process, the separation factor $\left(\mathrm{R}_{\mathrm{L}}\right)$ is calculated from:

$$
\mathrm{R}_{\mathrm{L}}=\frac{1}{1+\mathrm{bCo}}
$$

$\mathrm{b}=$ Langmuir constant for adsorption energy

$\mathrm{C}_{\mathrm{o}}=$ Initial Concentration

When $\mathrm{R}_{\mathrm{L}}>1$, the adsorption process is unfavourable; $\mathrm{R}_{\mathrm{L}}=1$, it is linear; when $0<\mathrm{R}_{\mathrm{L}}<1$, adsorption is favourable; and when $R_{L}=0$ it is irreversible Weber et al. (1974). The $R_{L}$ value obtained for the adsorption process under consideration was 0.043 which falls between 0 and 1 and this confirmed that adsorption process is favourable (Arivoli et al. 2007b).

\section{FREUNDLICH ADSORPTION ISOTHERM}

After fitting the adsorption data using the Freundlich adsorption isotherm, the Freundlich adsorption constants obtained are $\mathrm{n}=0.2321, \mathrm{~K}_{\mathrm{f}}=0.8935$ and the correlation coefficient, $\mathrm{R}^{2}=0.7373$ (Fig. 10).

Freundlich constants $\left(\mathrm{K}_{\mathrm{r}}\right.$ and $\left.\mathrm{n}\right)$ indicate whether the sorption is favourable or unfavourable, (Renmin et al. 2005). The intercept is an indication of sorption intensity. A relatively slight slope $\mathrm{n} \ll 1$ indicates that the sorption intensity is good over the entire range of concentration studied while a steep slope of $n>1$ indicate that sorption intensity is good at high concentration but much less at lower concentration, (Mohanty et al. 2006). A high value of $\mathrm{K}_{\mathrm{f}}$ is indicative of

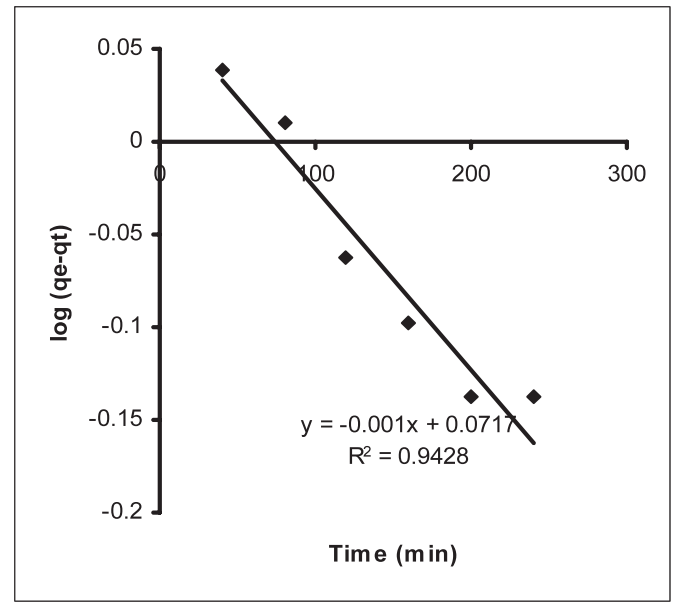

FIG. 12. Graph of $\log \left(\mathrm{q}_{\mathrm{e}}-\mathrm{q}_{\mathrm{t}}\right)$ versus Time (Lagergren plot). high sorption capacity. The low value of $\mathrm{K}_{\mathrm{f}}(0.8935)$ observed in this work and the correlation coefficient $\left(\mathrm{R}^{2}=0.7373\right)$ shows that the Freundlich adsorption isotherm does not satisfactorily fit the experimental data.

\section{TEMKIN ADSORPTION ISOTHERM}

The Temkin adsorption potential $\mathrm{K}_{\mathrm{T}}$ of chromate ion on hematite was 1.029 and the constant $\mathrm{b}_{\mathrm{T}}$, related to the heat of adsorption was $1.682 \mathrm{KJ} \mathrm{mol}^{-1}$ and the correlation coefficient, $R^{2}=0.9539$ (Fig. 11). The low values of the Temkin constants in this study indicate a weak interaction between sorbate and sorbent, (Horsfall et al. 2005), (Adouby et al. 2007). The coefficients of correlation $\left(\mathrm{R}^{2}\right)$ indicated that the Langmuir (0.9276) and Temkin (0.9539) isotherms fitted the adsorption data for chromate ion better than the Freundlich (0.7373) isotherm (Table 4).

\section{ADSORPTION KINETICS PSEUDO-FIRST ORDER KINETICS}

The pseudo-first order kinetics has been used to analyse the adsorption data to test how it fits with time (Fig. 12).

\section{PSEUDO-SECOND ORDER KINETICS}

The pseudo-second order kinetics was also used on the adsorption data of chromium on hematite (Fig. 13).

The coefficient of correlation for the first order rate constant was lower than that of the pseudo-second order model. It was observed that the $\mathrm{q}_{\mathrm{e}}$ value from the experiment did not agree with the $\mathrm{q}_{\mathrm{e}}$ value obtained

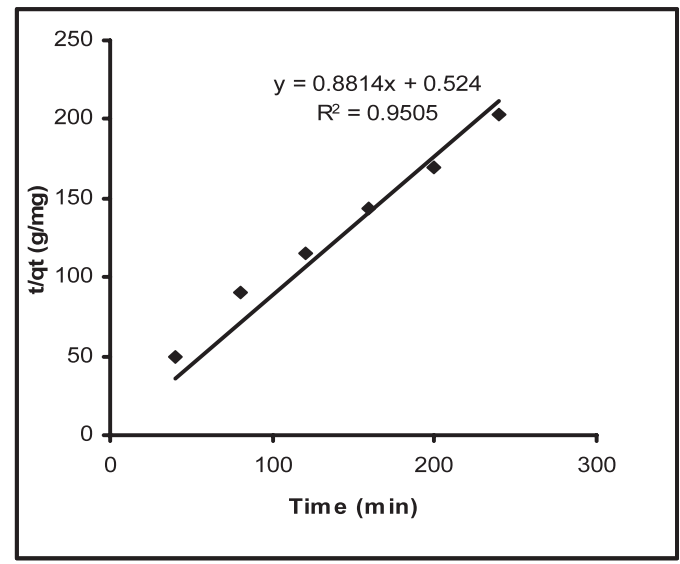

FIG. 13. Graph of $t / \mathrm{q}_{\mathrm{t}}$ against Time. (Pseudo-second order plot). 


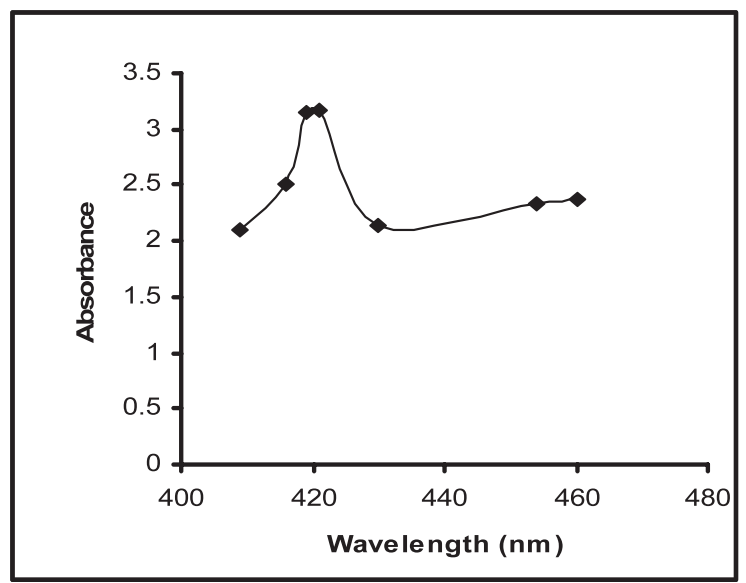

FIG. 14. Graph of Absorbance versus Wavelength.

from pseudo-first order plots. This indicates that pseudo-first order kinetics is not sufficient to describe the mechanism of chromate-hematite interactions. The kinetics can therefore be better described by the pseudosecond order kinetic (Table 5)

The plot of $t / q_{t}$ versus $t$ for pseudo-second order model (Fig. 13) yielded a very good straight line (correlation coefficient, $\mathrm{R}^{2}=0.9505$ ). The pseudosecond order rate constant was $0.312 \mathrm{~g} \mathrm{mg}^{-1}$. The theoretical value of $\mathrm{q}_{\mathrm{e}}$ also agrees very well with the experimental value. Both facts suggest that the adsorption of chromate ions by hematite follows the pseudosecond order kinetic model (Ye et al. 2008).

\section{CONCLUSION}

Hematite has been found to be an effective adsorbent for the removal of chromium from aqueous solution. The adsorption of chromium was found to be dependent on initial concentration of metal ion, $\mathrm{pH}$, ionic strength, and agitation time as expected. The maximum adsorption

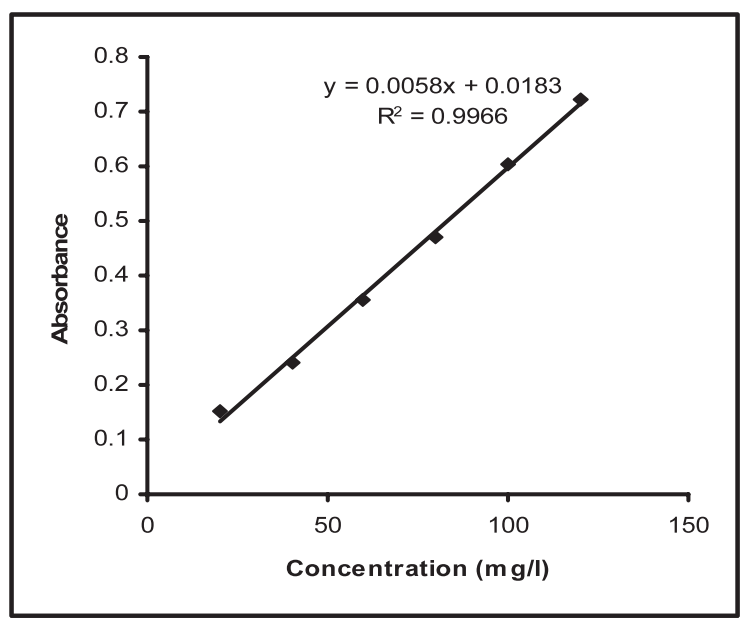

FIG. 15. Calibration graph of chromate solution.
Table 5. Kinetic parameters and correlation coefficient.

\begin{tabular}{lclc}
\hline & $\mathrm{q}_{\mathrm{e}}(\mathrm{mg} / \mathrm{g})$ & \multicolumn{1}{c}{$\mathrm{K}$} & $\mathrm{R}^{2}$ \\
\hline Pseudo-first order & 1.18 & $0.0023 \mathrm{~min}^{-1}$ & 0.9428 \\
Pseudo-second order & 1.908 & $0.312(\mathrm{~g} / \mathrm{mg})$ & 0.9505 \\
\hline
\end{tabular}

capacity obtained was $1.908 \mathrm{mg} / \mathrm{g}$ and the maximum removal of chromium was observed at $\mathrm{pH} 6$ with initial concentration of $60 \mathrm{mg} / \mathrm{l}$. The equilibrium adsorption data showed satisfactory fitting with Langmuir and Temkin adsorption isotherms and the adsorption kinetic of the system conforms better to the pseudo-second order kinetics.

\section{LITERATURE CITED}

ADOUBY, K., L. C. KOFFI, W. N. EBOUA, AND B. YAO. 2007. Removal of heavy metal ion $\left(\mathrm{pb}^{2+}, \mathrm{Cu}^{2+}\right)$ in aqueous solutions by pterygota macrocarpa sawdust. J. Appl. Sci. 7(14):1864-1872.

AJOUYED, O., C. HUREL, M. AMMARI, L. B. ALLAL, AND N. MARMIER. 2010. Sorption of $\mathrm{Cr}(\mathrm{VI})$ onto natural iron and aluminium (oxy) hydtoxides. Effects of $\mathrm{pH}$, ionic strength and initial concentration. J. Hazardous Materials 174(1-3):616-622.

ARIVOLI, S. S., S. JAIN, AND T. RAJACHANDRASEKAR. 2006. Cobalt adsorption on a low cost carbon-kinetics, equilibrium and mechanistic Studies. Material Sci. Res. 3:241-250.

ARIVOLI, S., AND M. HEMA. 2007. Comparative study on the adsorption kinetics and thermodynamics of dyes onto acid activated low cost carbon. Intern. J. Physical Sci. 2:10-17.

ARIVOLI, S., B. R. VENKATRAMAN, T. RAJACHANDRASEKAR, AND M. HEMA. 2007. Adsorption of ferrous ion from aqueous solution by low cost activated carbon obtained from natural plant material. Res. J. Chem. Environ. 17:70-78.

BARTLETT, R. J., AND B. JAMES. 1983. Behaviour of Chromium in soil VI. Interactions between oxidation-reduction and organic complexation. J. Environ. Sci. Quality 12:177-181.

BLOWES, D. W., C. J. PTACER, AND J. L. JAMBOR. 1997. In-situ remediation of chromate contaminated Groundwater using permeable Reactive walls. J. Environ. Sci.Tech. 31:3348-3357.

DENG, B., AND C. KIM. 2007. Kinetic Study of hexavalent Cr(VI) reduction by hydrogen sulfide through goethite surface catalytic reaction. Geochem. J. 41:397-405.

EARY, L. E., AND D. RAI. 1988. Chromate Removal from Aqueous wastes by Reduction with ferrous ion. J. Environ. Sci. and Tech. 22:972-977.

EARY, L. E., AND D. RAI.D. 1988. Kinetics of chromate Reduction by Ferrous ions, derived from Hematite and Biotite at $25^{\circ} \mathrm{C}$. Amer. Journ. Sci. 289:180-213.

EL-CHAGHABY, G. A., N. T. ABDEL-GHANI, AND R. M. ELNASHAR. 2008. Removal of $\mathrm{Cr}$ (III) and $\mathrm{Pb}$ (II) from solution by adsorption onto Casuarina Glauca tree leaves. 7(7):3126-3133.

FENDORF, S. E., AND L. I. G. 1996. Kinetics of Chromate Reduction by Ferrous ions. Environ. Sci. Tech. 30(5):1614-1617.

GUBIN, S. P. 2009. Magnetic nanoparticles, Wiley-VCH Verlag GmPH and Co, Weinheim. 1 Ed. Euro. 14:470.

GUY, H., D. STUBEN, AND Z. BERNER. 2007. Removal of Arsenic from aqueous solution by natural stelerite and hematite. Applied Geochem. 22:1039-1051.

HORSFALL, M., AND I. S. AYEBAEMI. 2005. Equilibrium sorption study of $\mathrm{Al}^{3+}, \mathrm{Co}^{2+}$ and $\mathrm{Ag}^{+}$in aqueous solutions by fluted pumpkin (Telfaira Occidentalis Hook f) waste Biomass. Acta.Chem. Slov. 52:174-181. 
JAMES, B. R. 1996. The challenge of remediating chromium contaminated soil. J. Environ. Sci. Tech. 30:248A-251A.

KOSMULSKI, M. 2004. pH-dependent surface charging and points of zero charge II update. J. Colloid and Interface Sci. (275):214-224.

KRISHNA, D. G., AND G. BHATTACHARY. 2002. Adsorption of methylene blue on Kaolinite. Applied Clay Sci. 20:295.

LU, J., C. DIARONG, AND J. XIULING. 2006. Fabrication, Characterization and Formation Mechanism of Hollow Spindle-like Hematite via Solvothermal Process. J. Colloid Interface Sci. 303(2):437-443.

MEGAT HANAFIAH, M. A. K., W. S. WAN, H. ZAKARIA, AND S. C. IBRAHIM. 2007. Batch study of Liquid-Phase Adsorption of lead ions using Lalang (Imperata cylindrical) leaf powder. J. Bio. Sci. 7(2):222-230.

MOHANTY, K., M. JHA, B. C. MEIKAP, AND M. N. BISWAS. 2006. Biosorption of $\mathrm{Cr}$ (VI) from aqueous solutions by Eichhornia Crassipes. J. Chem. Engin. 11:71-77.

NOH, J. S., AND J. A. SCHWARZ. 1989. J. Colloid Interface Sci. 130:157.

RAI, D., B. M. SASS, AND D. A. MOORE. 1987. Chromium (III) Hydrolysis constants and solubility of Chromium (III) Hydroxide. Inorganic Chemistry 26:345-349.

RENMIN, G., S. YINGZHI, C. JIAN, L. HUIJUN, AND Y. CHAO. 2005. Effect of chemical modification on dye adsorption capacity of peanut hull. Dyes and pigments 67:17a.
SCHWERTMANN, U., P. CAMBER, AND E. MURAD. 1985. Properties of Goethite of varying crystallinity. Clay and Clay Min. 33:369-378.

SCHWERTMANN, U., AND R. M. CORNELL. 2007. Iron Oxides in the laboratory,Preparation and characterization. WileyVCHVerlagGmbH, Weinheim, Germanydoi:10.1002/ 9783527613229.fmatter.

SINGH, D. B., G. S. GUPTA, AND D. C. RUPAINWAR. 1993. The use of hematite from chromium(VI) removal. Pollution Research Laboratory, Department of Applied chemistry, Institute of Technology, Banaras Hindu University Varanasi221 005, India. J. Environ.Sci.Health A28(8):1813-1826.

WANG, X., C. XIANGYING, M. XUCHU, AND Z. HUANGUI. 2003. Low-Temperature Synthesis of $\alpha \mathrm{Fe}_{2} \mathrm{O}_{3}$ Nanoparticle with a Closed Cage Structure. Chem. Phys. Lett. 384(4-6):391-393.

WEBER, T. W., AND R. K. CHAKRABORTI. 1974. Pore and solid diffusion models for fixed bed adsorbers. J. Amer. Inst. of Chem. Engin. 20:228.

YE, L., W. YU-HUA, AND H. CHUA-BING. 2008. Removal of anionic ions from single material solution by bauxite tailings modified with $\mathrm{FeCl}_{3} \cdot 6 \mathrm{H}_{2} \mathrm{O}$ " J. Cent. South Univ. Tech. 15:656-662.

YIN, S., AND D. E. ELLIS. 2009. DFT studies of Cr(VI) complex adsorption on hydroxylated hematite (1102) surfaces. Surface Sci. 603(4):736-746 http://www.eformulae.com/chemistry/specific. php. http://www.mindat.org/min-1856 html 